$\overline{\text { General }}$

\title{
Individuals lacking ridge detail: A case study in adermatoglyphia
}

\author{
Heather Isla Cook MSc ${ }^{1}$ | Karl Harrison PhD ${ }^{1}$ | Helen James ${ }^{2}$
}

\author{
${ }^{1}$ Alecto Forensic Services Ltd., Watchfield, \\ Oxfordshire, UK \\ ${ }^{2}$ Thames Valley Police, Kidlington, Oxon, \\ UK \\ Correspondence \\ Karl Harrison, PhD, Alecto Forensic \\ Services Ltd., Watchfield, Oxfordshire, UK. \\ Email: k.harrison@cranfield.ac.uk
}

\begin{abstract}
Adermatoglyphia is a very rare autosomal-dominant condition that is genetically inherited and causes an individual to be born without conventional ridge detail on either their palmar or plantar surfaces (the fingers and palms of the hands and the toes and the soles of the feet). While adermatoglyphia has been the focus of medical and genetic research, no previous research has been conducted with regard to the forensic recovery and identification of marks from an adermatoglyphic individual. By observation of ridge detail donated by an adermatoglyphic subject, the study uses different methods in order to capture fingermarks (methods include: inked capture, livescan (biometric) capture, cyanoacrylate fuming, ninhydrin enhancement, and physical developer). Unusually, the purpose of this paper ends up presenting a number of examples of an absence of evidence; unsuccessful attempts made to capture and enhance fingerprint ridge detail. This is determined over a range of standard means including "live" donations by the adermatoglyphic subject onto the Livescan system, and enhancements of latent donations. The subject shows to leave either insubstantial fingermarks with no detail, or no mark whatsoever.
\end{abstract}

\section{KEYWORDS}

adermatoglyphia, biometric systems, fingerprints, ridge detail

\section{1 | INTRODUCTION}

This project presents the first case observation of ridge detail donated by an adermatoglyphic subject and compares both the powder and chemical enhancement of adermatoglyphic subject-donated marks with those of a non-affected positive control donor. Expert interpretation of the marks suggested that in appearance in live casework, such marks might be mistakenly identified as those of the very elderly or gloved fingermarks.

Globally, fingerprints are held up as a unique identifying biometric characteristic, and as such constitute a primary source of identification in terms of immigration border control, criminal investigation and the identification of the deceased, either individually or in the context of mass fatality incidents. While the term "uniqueness" has been a point of some debate [1], fingerprints have been the subject of empirical study [2], enshrined in the pragmatic view of US legislators:

"[I]f it is acknowledged that fingerprints are unique and permanent, then the theory of fingerprints, that everyone has one which can be compared with unknown prints seems to be sound and not in need of testing" [3].

Fingerprint Identifications from crime scene marks are made using the ACE-V methodology. Fingerprint Experts analyze, compare, and evaluate the mark (from the crime scene) and the fingerprint (on the tenprint form). Any subsequent identification is 
then verified by peers. Fingerprint Experts consider pattern type, ridge characteristics, creases, and scars to enable the formation of an opinion on identification. The levels of detail present in a mark have been conceptualized by Ashbaugh [4] in the following manner: 1st level detail (fingerprint pattern), 2nd level detail (ridge characteristics), and 3rd level detail (scars, creases, edgeoscopy, and poroscopy). Fingerprint Experts need a coincident sequence for the mark to be identified to the fingerprint. This is that the ridge characteristics are the same, the same relationship to each other with sufficient in agreement and none in disagreement. Visible ridge characteristics in a coincident sequence are required to give evidence in court.

A very small proportion of a percentage of individuals are affected by the condition adermatoglyphia, which is characterized by an absence of ridges and other details associated with the formation of fingerprint on the fingers, palms, toes, and soles of their feet (dermatoglyphs). Adermatoglyphic individuals appear to be affected across all ridge-bearing tissue, resulting in either entirely flat surfaces of skin, or surfaces which feature unusually large amounts of pathological creasing. This condition is exceptionally rare; in a study of 2013 data from the Lebanese Ministry of Internal Affairs of people applying for biometric identity cards, $259(0.18 \%)$ were noted as having no fingerprints [5]. A total of 137 of these 259 were noted as having a dermatologic condition resulting in adermatoglyphia, with the others falling into four other categories of loss: burns, amputations, dystonia, and wounds. Adermatoglyphia has yet to be properly documented within forensic research. It is unclear how the disorder interferes with the development of ridge patterns, as they are believed to be formed by the flow of amniotic fluid and the position of the fetus in the uterus, which changes the growth patterns of the cells on the fingertips and determines the structure of fingerprints [6]. Genetic studies of adermatoglyphia have focused on the gene SMARCAD1, which seems to have a role in dermatoglyphs development [7].

Adermatoglyphia has more recently been nicknamed the "immigration delay disease" (a term coined by Burger et al., [8]). The growth in the application of biometric controls to international travel, including the donation of fingerprints on entering a country (such as when entering the United States, [9]), has resulted in adermatoglyphic individuals being challenged at national borders [10].

Scientific literature discussing adermatoglyphia has focussed on the genetic causes of Naegelie-Franceschetti-Jadassohn syndrome (NFJ), with barely any focus given to the forensic implications that this condition could result in. Itin et al's 1993 paper detailed the re-examination of the original Swiss family in which NFJ syndrome was first observed 65 years earlier [11]. The authors examined 62 members of the family (only 14 of which were affected by NFJ). Four of the 14 were by then deceased by 1993, leaving only 10 that could be physically examined. All ten living affected subjects in the study family lacked dermatoglyphs. Four of the ten had congenital malalignment of the toenails, which had not previously been associated with the condition. NFJ is an ectodermal dysplasia, a genetic disorder, which effects the development of teeth, nails, sweat glands, and hair. Medically, adermatoglyphia is believed to be a symptom of an underlying genetic condition such as NFJ. In addition, there are however reported cases of isolated adermatoglyphia, where individuals do not present other symptoms associated with NFJ and rather just feature the lack of dermal ridges on both hands and feet, and also present reduced sweating (hypohidrosis) in the hands and feet.

More recent research by Cohen (2017) has been conducted into the loss of fingerprints due to the treatment of breast cancer with Capecitabine (an oral 5-fluorouracil prodrug) [12]; however, this paper does not detail the condition and its effects from a Forensic Science perspective. A paper written by Sarfraz in 2019 [13] highlights the biometric implications of adermatoglyphia. This paper, however, focuses on the biometric effects of the condition, and not the implications of the condition from a forensic outlook.

It has been suggested that the amount of people suffering from this condition is approximately 1 case in 2-4 million people, and adermatoglyphia has been reported in individuals and families from Switzerland, Japan, Italy, and the United Kingdom [14]. While this is a tiny proportion, it still represents $65-130$ people living with adermatoglyphia within the total population of the four countries in which its occurrence has been reported, and the levels of occurrence in Lebanon suggest that this figure might be higher still [5].

This study has identified an adermatoglyphic female living in the United Kingdom. At the time of this study, she was in her twenties. The adermatoglyphic donor in this study is the only living member of her family to be affected by the condition, and on the basis of presented symptoms (adermatoglyphia and hypohidrosis, described below) is believed to not suffer from NFJ syndrome. The pads of her fingers and toes are completely flat, bar numerous creases. Her palms and soles of her feet are also extremely creased with some flat smooth areas. There are no dermatoglyphs (ridges) present on the hands or feet of the donor. A lack of fingerprints cannot be confirmed as a trait throughout the donor's family. The donor's father and only sibling are unaffected, while her mother presents with partial, poorly formed fingerprints. It is believed that the condition may have been passed from the donor's maternal grandmother, who is remembered has having no fingerprints (however, this family member is now deceased).

In addition to a lack of visible ridges, the donor also suffers from the adermatoglyphic symptom of chronic palmar and plantar hypohidrosis. She produces no evident eccrine secretions on her hands and feet, which under normal circumstances would facilitate the transfer of ridge detail patterns that form the basis of forensic latent fingerprint examination.

\section{2 | METHOD}

The adermatoglyphic donor's fingermarks were subjected to a range of routine fingerprint enhancement and examination techniques in 
the Fingerprint Bureau, Enhancement Laboratory and Detention Suite of Thames Valley Police. The results of these examinations were then assessed by a Thames Valley Police Fingerprint Expert.

The adermatoglyphic donor's fingermarks were captured via numerous media:

1. Inked tenprint capture.

2. Livescan capture system (3 scans of all fingers and both thumbs).

3. Cyanoacrylate fuming of handling marks deposited on an aluminum drinks can.

4. Cyanoacrylate fuming of marks deposited on an acetate sheet using a synthetic sebaceous wax.

5. Ninhydrin enhancement of marks deposited on paper (four fingers of the right hand, repeated five times).
6. Physical Developer enhancement of marks deposited on paper (four fingers of the right hand, repeated five times).

\section{RESULTS}

In the case of the adermatoglyphic subject of this study, only 3rd level detail in the form of creases, but some ridges, is apparent. Both the lifts and inked impressions taken directly from the subject can be seen to feature creases in common from the fingers. A comparison of the creases visible in both the lifted and inked impressions of the subject's fingers and palms indicates that it would be possible to confirm the subject's identity had lifts been taken from a body and been subject to direct comparison with reference marks.

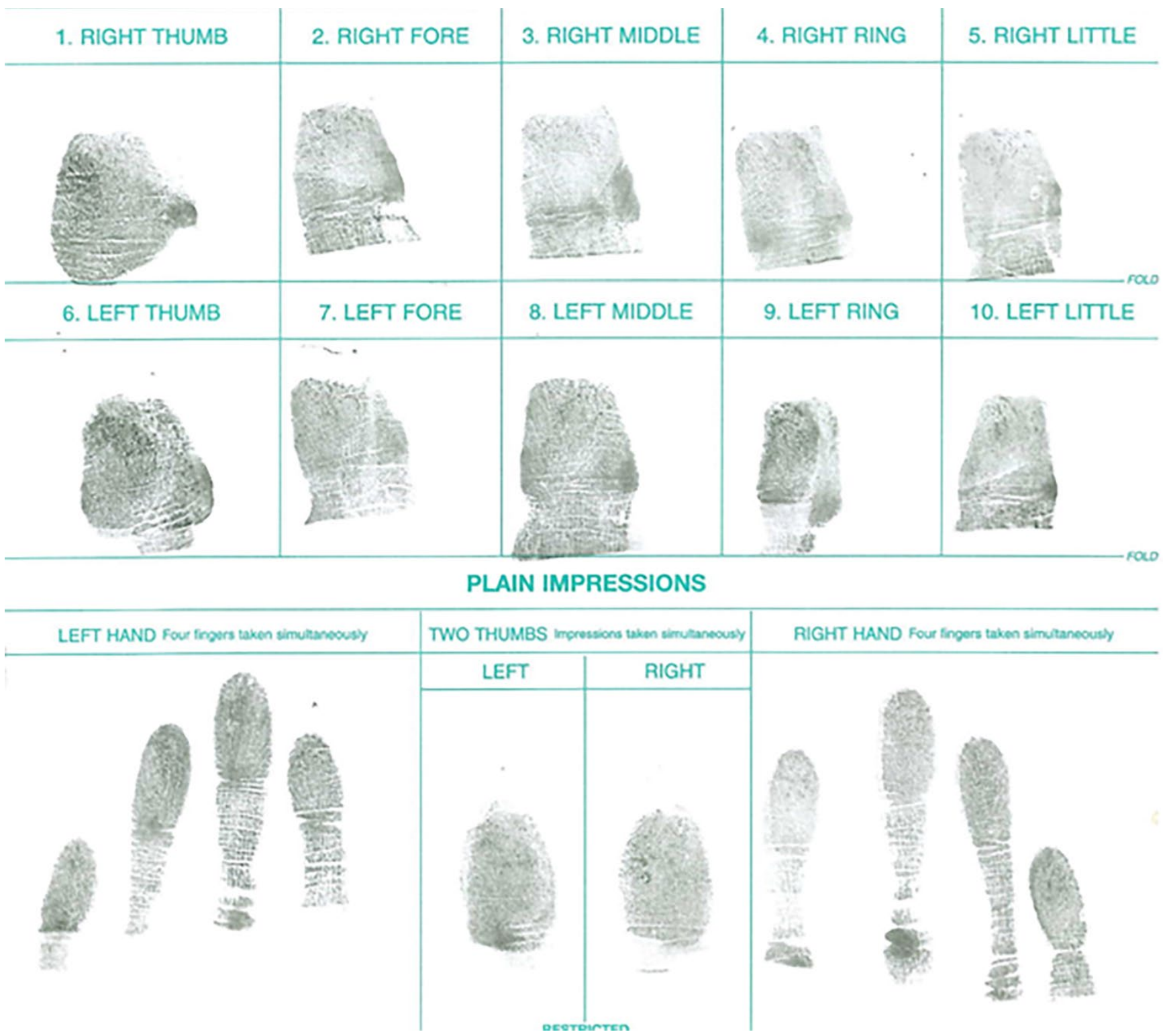

FIGURE 1 Inked capture of fingermarks taken from dermatoglyphic subject. Capture shows lack of typical fingermark details [Color figure can be viewed at wileyonlinelibrary.com] 


\section{1 | Inked tenprint capture}

The experimental subject's fingers and palms were coated with ink rolled across a copper plate and positioned on a standard fingerprint elimination form, providing a series of rolled and placed fingermarks. These provided the reference for the subject's fingers can be seen in Figure 1.

\subsection{Livescan capture system}

A Thames Valley Police Detention Officer assisted the donor in depositing her fingermarks on the capture screen. Following an initial scan of the subject's hands, the Detention Officer decided that the hands of the individual were too dry (due to no sweat being produced) so a wet wipe was used in order to moisten the hands. The Livescan system returned a "Poor Detail" error, so hand cream was applied to the subject. Figure 2 shows the natural scans, and Figure 3 shows the wet-wipe moistened prints.

The lack of ridge detail in all of these fingermarks was immediately apparent. Rather, the fingermarks preserve a notable presence of creases, the broadest of which are set transversely across each mark. In addition, pore heads appeared as dark specks concentrated at the tips of the distal phalanges.

The Detention Officer at the Custody Suite commented that although she had seen pores evident on normal prints, the pores on the prints belonging to the Adermatoglyphic individual were large in comparison and were clustered together. After each sequential scan and each individual finger scan (including thumbs), the system continued to show an error message stating that the image quality was poor.

The detailed image presented in Figure 4 gives the highest resolution image of the adermatoglyphic subject's fingermarks. The right and left thumb prints presented here exhibit no conventional ridge detail, but feature extensive pathological creasing far beyond that expected, given the age of the subject. These creases are particularly notable running transversely across the pad and are broadest below where the core of a fingerprint pattern might be expected to be present. The dark speckling of pore heads are particularly evident to the distal (tips) and medial (ulnar) aspects of both thumb pads.

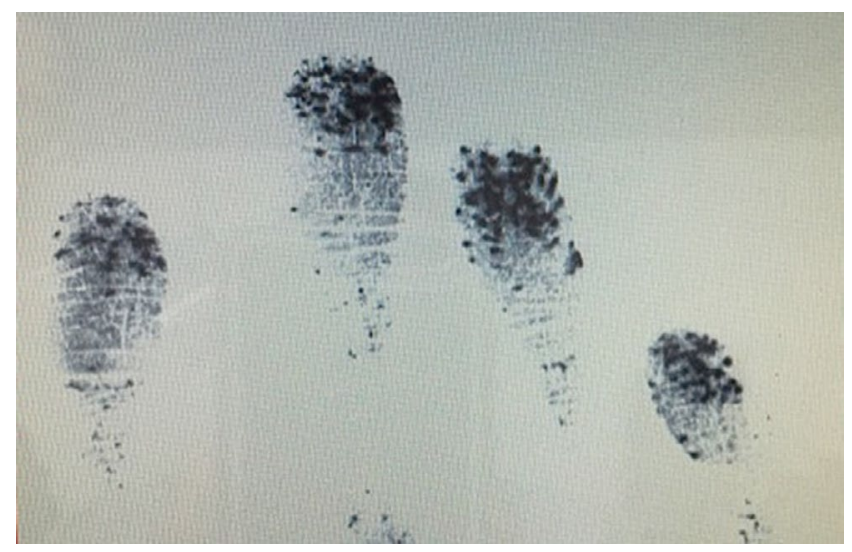

FIGURE 2 Livescan image of the right hand of the adermatoglyphic subject [Color figure can be viewed at wileyonlinelibrary.com]

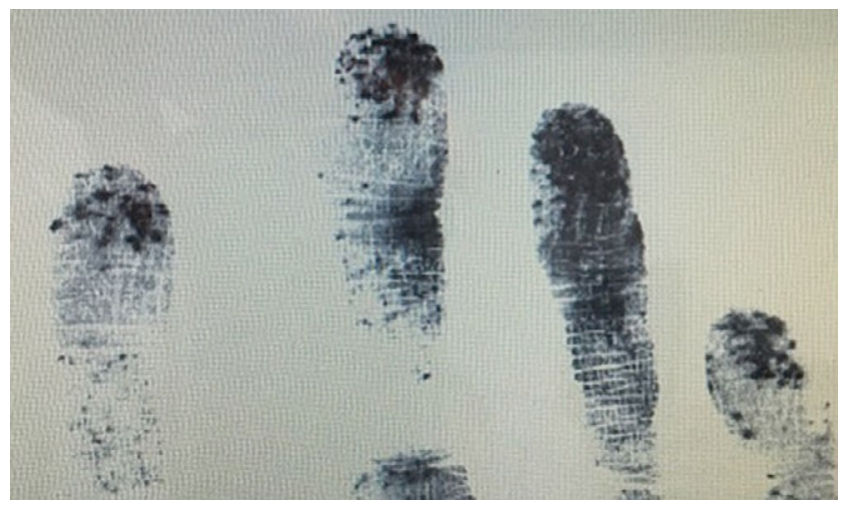

FIGURE 3 Livescan image of the right hand of the adermatoglyphic subject following the application of a wet wipe [Color figure can be viewed at wileyonlinelibrary.com]

\section{3 | Cyanoacrylate fuming of handling marks deposited on an aluminum drink can}

An aluminum drink can was handled by the adermatoglyphic donor and an unaffected positive control donor. The can was then subjected to cyanoacrylate (superglue) fuming in order to develop fingermarks via the enhancement of deposited amino acids, as per Thames Valley Police protocols. While the positive control prints produced clear ridge detail on enhancement, the adermatoglyphic fingermarks were entirely indistinct (see Figure 5). Not only was no ridge detail apparent, but in addition no specific finger outlines were developed, suggesting a minimal production of amino acids by the adermatoglyphic donor.

In the opinion of the Fingerprint Expert, there was no evidence present to suggest the adermatoglyphic subject touched the can.

\subsection{Cyanoacrylate fuming of marks deposited on an acetate sheet using a synthetic sebaceous wax}

The fingers of both hands of the adermatoglyphic subject were introduced to a pad of synthetic sebaceous material. The fingers were then applied to an acetate sheet, on which five repeats of each finger were placed in a depletion sequence, with each press of the finger depositing less synthetic sebaceous material than the previous one. As expected, the fingermarks deposited at the start of the depletion sequence produced the clearest outlines of finger impressions (Figure 6), with clarity decreasing as the depletion series moved along the grid. On both fingers 1 and 2 (The two prints shown in Figure 6), the pathological creasing of the pads of the fingers is visible. The speckled pore heads apparent in the Livescan images above exhibit as white speckling to the top of the fingermarks in Figure 6.

The Fingerprint Expert noted faint impressions evident from finger 1 , with possible faint vertical ridges visible, horizontal creases visible to the right side of the mark. When trying to compare the creases disclosed in these marks with the adermatoglyphic subject's inked impressions, finger 1 and finger 2 seem to be more consistent with the creases visible in the subject's left forefinger (LF) and left 


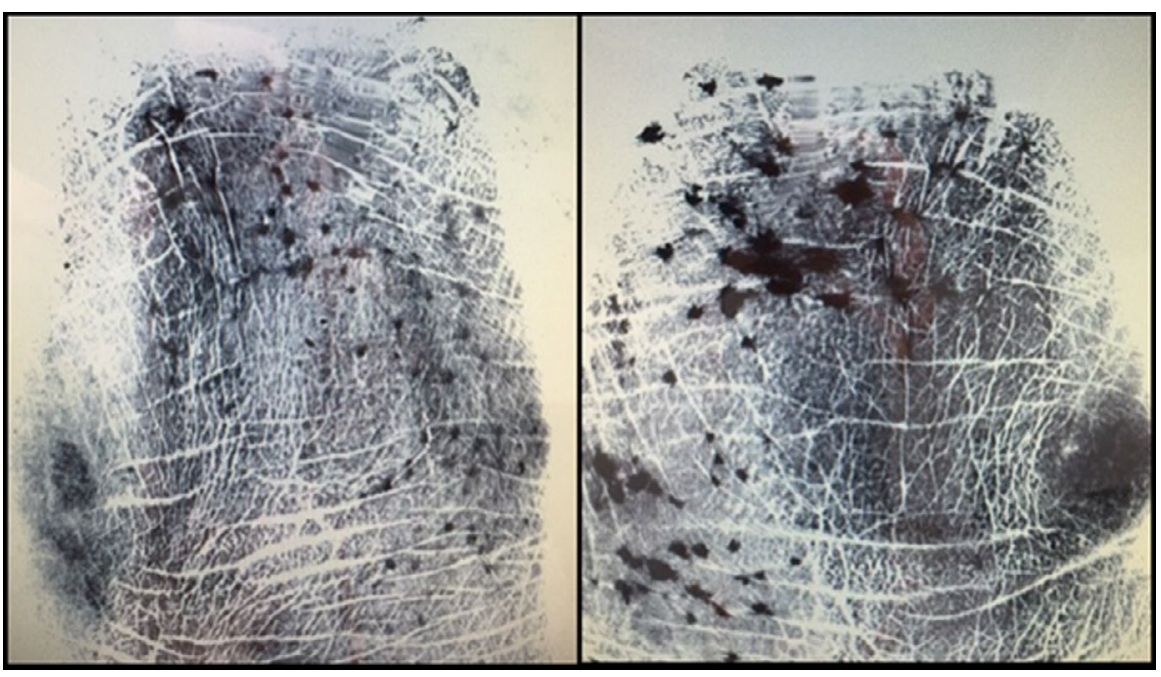

FIGURE 4 Livescan image of left and right distal thumb pads of the adermatoglyphic subject, showing lack of typical ridges [Color figure can be viewed at wileyonlinelibrary.com]

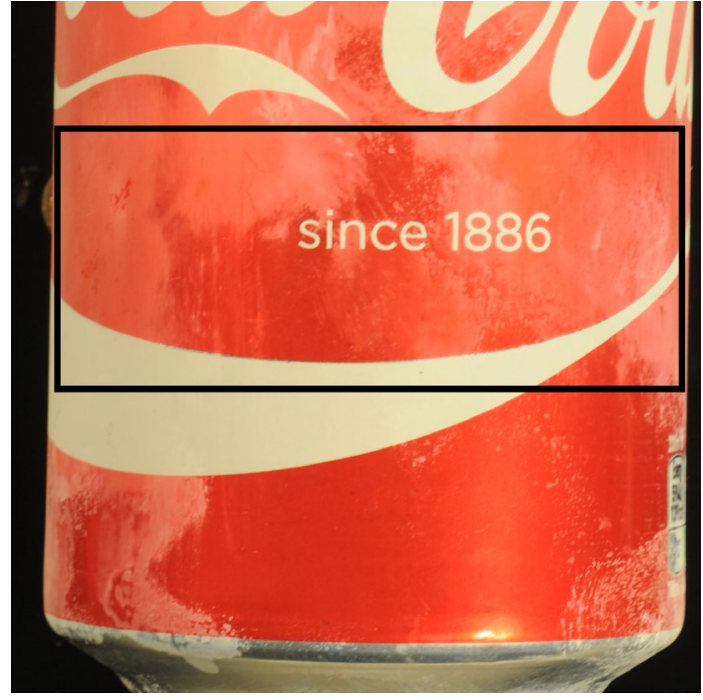

FIGURE 5 Aluminum drink can follow cyanoacrylate fuming. The black box indicates the area of handling by the adermatoglyphic subject [Color figure can be viewed at wileyonlinelibrary.com]

middle finger (LM) rather than the right forefinger (RF) and right middle finger (RM); however, there is insufficient detail disclosed to form an opinion. Were these marks developed at and taken from a crime scene they would all be coded as "limited ridge detail," meaning there is insufficient detail disclosed in the mark for identification purposes.

\subsection{Ninhydrin enhancement of marks deposited on paper}

The adermatoglyphic subject was asked to donate fingermarks on a sheet of A4 printer paper in a gridded depletion sequence similar to that outlined on acetate above. This sheet was treated with ninhydrin to enhance any latent marks left

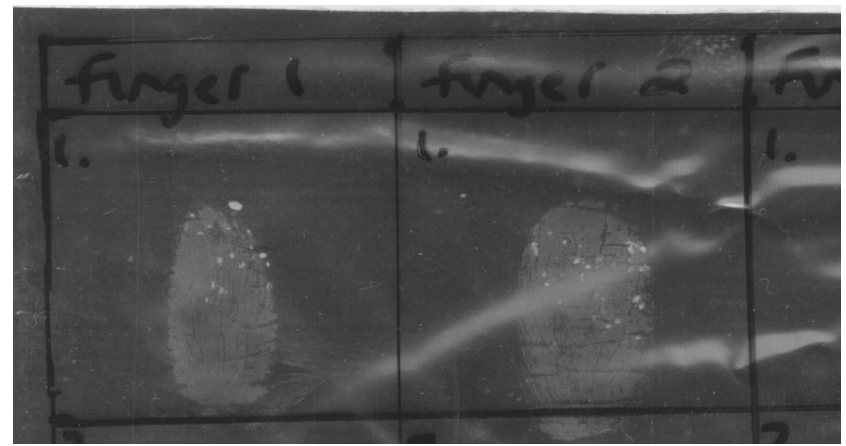

FIGURE 6 Cyanoacrylate-enhanced marks deposited by the adermatoglyphic subject using synthetic sebaceous wax

via the deposition of amino acids into the porous substrate of the paper.

Ninhydrin enhancement revealed light speckling around the pore heads to the top of each of the donor's marks, but no other finger outline or creasing was revealed through this method.

\section{6 | Physical developer enhancement of marks deposited on paper}

The adermatoglyphic subject was asked to donate fingermarks on a sheet of A4 printer paper in a gridded depletion sequence similar to that outlined on acetate above. Five repeats of the four fingers of her right hand were taken, and the paper was then exposed to Physical Developer, to enhance any fingermark detail preserved in the sebaceous portion of the deposited latent mark. As with cyanoacrylate enhancement, the lack of any native sweat products in the fingerprints resulted in no fingermarks being deposited. The speckling that had revealed the presence of pore heads in Livescan imaging, cyanoacrylate fuming, and ninhydrin 


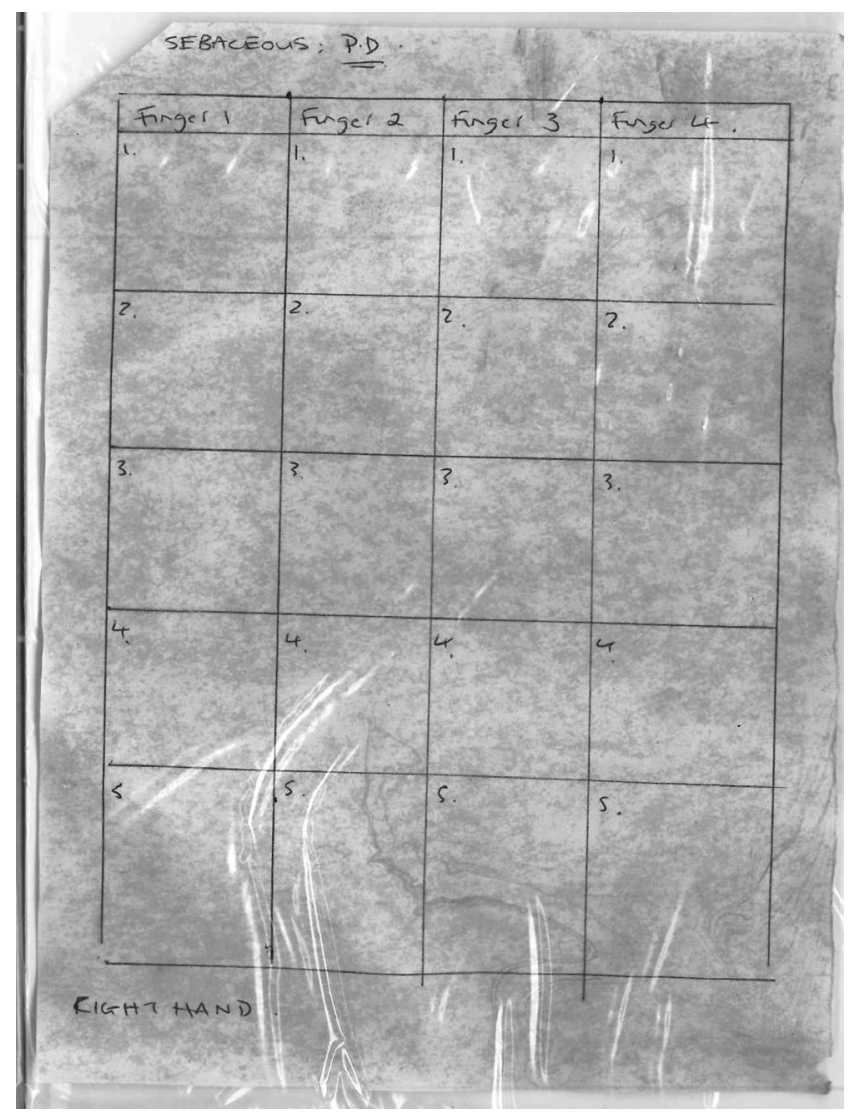

FIGURE 7 Depletion series donation grid of marks left by the adermatoglyphic subject enhanced with physical developer. As evidenced by the grid, there was no enhancement detectable

enhancement was not apparent in the physical developer enhancement (Figure 7).

\section{DISCUSSION}

Unusually, the purpose of this paper has been to present a number of examples of an absence of evidence; unsuccessful attempts made to capture and enhance fingerprint ridge detail. Over a range of standard means of ridge detail capture, including both "live" donations by the adermatoglyphic subject onto the Livescan system, and enhancements of latent donations, the subject has been shown to have left either insubstantial fingermarks with no detail, or no mark whatsoever.

Collection techniques with higher levels of resolution, such as Livescan collection, or cyanoacrylate fuming of an acetate sheet following the introduction of a synthetic sebaceous wax as a carrier substance succeeded in revealing minor characteristics that might indicate to a Fingerprint Expert the involvement of an adermatoglyphic subject; a lack of ridge detail combined with a preponderance of pathological creases, particularly those passing transversely under the "core" of the distal pad impression. In addition, characteristically large pore heads grouped toward the top and ulnar surfaces of the finer pads were noted. It is hoped that future work will return to this subject to assess the stability of pathological creases that might be able to form a means of manual comparison by a Fingerprint Expert.

While the Livescan system produced a high-resolution image of the adermatoglyphic subject's fingers and palms, it was incapable of coding these images, and rejected them as lacking detail. This issue of the failure of automated recognition systems is central to problems faced by adermatoglyphic individuals operating in a world secured by ever more biometric controls, whether at a national border, or central to security systems on smartphones and laptops.

The prevalence of sufferers of NFJ or the appearance of isolated adermatoglyphic individuals has been assessed by geneticists as being one in millions, and it is consequently highly unlikely that the fingermarks of any such people will present themselves for collection by a Crime Scene Investigator, enhancement by a Forensic Chemical Technician, or assessment by a Fingerprint Expert. However, if investigators have cause to suspect the involvement of an adermatoglyphic subject in crime, then the propensity of their fingermarks to mimic those of the very elderly, or appear similar to the outlines of glovemarks, or even to remain entirely invisible should be considered. This paper offers a characterization of pathological creases and pore heads that provide some defining features in such circumstances.

\section{ACKNOWLEDGMENTS}

The authors would like to thank the staff of Thames Valley Police for their assistance in producing this work, and the family of our experimental subject for the attention paid to their lack of dermatoglyphs.

\section{REFERENCES}

1. Swofford HJ. Individualization using friction skin impressions: scientifically reliable, legally valid. J Forensic Identif. 2012;62(1):62-79.

2. Maltoni D. Handbook of Fingerprint Recognition. New York, NY: Springer, 2003.

3. United States v. Merritt, 2002 U.S. Dist. LEXIS 14711 (S.D. Ind. 2002).

4. Ashbaugh DR. Quantitative-qualitative Friction Ridge Analysis: An Introduction to Basic and Advanced Ridgeology. Boca Raton, FL: CRC Press, 1999.

5. Haber R, Helou J, Korkomaz J, Habre M, Ghanem A, Tomb R. Absence of fingertips with focus on dermatological etiologies: national survey and review. J Clin Dermatol. 2015;3(1):21-6.

6. Han Y, Ryu C, Moon J, Kim H, Choi H. A study on evaluating the uniqueness of fingerprints using statistical analysis. In: Park C, Chee S, editors. International Conference on Information Security and Cryptology (ICISC 2004). Lecture Notes in Computer Science. Vol 3506. Berlin/Heidelberg, Germany: Springer; 2005. p. 467-77. https://doi.org/10.1007/11496618_34.

7. Nousbeck J, Burger B, Fuchs-Telem D, Pavlovsky M, Fenig $S$, Sarig $O$, et al. A mutation in a skin-specific isoform of SMARCAD1 causes autosomal-dominant adermatoglyphia. Am J Hum Genet. 2011;89(2):302-7. https://doi.org/10.1016/j. ajhg.2011.07.004.

8. Burger B, Fuchs D, Sprecher E, Itin P. The immigration delay disease: adermatoglyphia-inherited absence of epidermal ridges. J Am Acad Dermatol. 2011;64(5):974-80. https://doi.org/10.1016/j. jaad.2009.11.013. 
9. U.S. Department of Homeland Security. New biometric technology improves security and facilitates U.S. entry process for international travellers. 2009. https://www.dhs.gov/xlibrary/assets/usvis it/usvisit_edu_10-fingerprint_consumer_friendly_content_1400_ words.pdf. Accessed 23 Sep 2020.

10. Stromberg J. Adermatoglyphia: The genetic disorder of people born without fingerprints. 2014. http://www.smithsonianmag.com/ science-nature/adermatoglyphia-genetic-disorder-people-bornwithout-fingerprints-180949338/. Accessed 23 Sep 2020.

11. Itin P, Lautenschlager S, Meyer R, Mevorah B, Rufli T. Natural history of the Naegeli-Franceschetti-Jadassohn syndrome and further delineation of its clinical manifestations. J Am Acad Dermatol. 1993;28(6):942-50. https://doi.org/10.1016/0190-9622(93)70135-G.

12. Cohen PR. Capecitabine-associated loss of fingerprints: report of capecitabine-induced adermatoglyphia in two women with breast cancer and review of acquired dermatoglyphic absence in oncology patients treated with capecitabine. Cureus. 2017;9(1):e969. https:// doi.org/10.7759/cureus.969.

13. Sarfraz N. Adermatoglyphia: barriers to biometric identification and the need for a standardized alternative. Cureus. 2019;11(2):e4040. https://doi.org/10.7759/cureus.4040.

14. Hussain S, Ahmed S. Identity dilemma: Naegeli-FranceschettiJadassohn syndrome. J Rawalpindi Med Coll. 2012;16(2):200-1.

How to cite this article: Cook HI, Harrison $\mathrm{K}$, James $\mathrm{H}$. Individuals lacking ridge detail: A case study in adermatoglyphia. J Forensic Sci. 2021;66:202-208. https://doi. org/10.1111/1556-4029.14597 